\title{
In vitro glucocorticoid sensitivity is associated with clinical glucocorticoid therapy outcome in rheumatoid arthritis
}

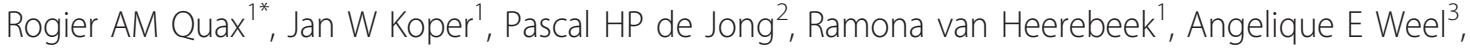 \\ Anne M Huisman ${ }^{4}$, Derkjen van Zeben ${ }^{4}$, Frank H de Jong ${ }^{1}$, Steven WJ Lamberts ${ }^{1}$, Johanna MW Hazes ${ }^{2}$ and \\ Richard A Feelders ${ }^{1}$
}

\begin{abstract}
Introduction: Genetic and disease-related factors give rise to a wide spectrum of glucocorticoid (GC) sensitivity in rheumatoid arthritis (RA). In clinical practice, GC treatment is not adapted to these differences in GC sensitivity. In vitro assessment of GC sensitivity before the start of therapy could allow more individualized GC therapy. The aim of the study was to investigate the association between in vitro and in vivo GC sensitivity in RA.

Methods: Thirty-eight early and 37 established RA patients were prospectively studied. In vitro GC sensitivity was assessed with dexamethasone-induced effects on interleukin-2 (IL-2) and glucocorticoid-induced leucine zipper (GILZ) messenger RNA expression in peripheral blood mononuclear cells (PBMCs). A whole-cell dexamethasonebinding assay was used to measure number and affinity ( $\left.1 / K_{D}\right)$ of glucocorticoid receptors (GRs).

In vivo GC sensitivity was determined by measuring the disease activity score (DAS) and health assessment questionnaire disability index (HAQ-DI) score before and after 2 weeks of standardized GC treatment.
\end{abstract}

Results: GR number was positively correlated with improvement in DAS. IL-2-EC 50 and GILZ-EC 50 values both had weak near-significant correlations with clinical improvement in DAS in intramuscularly treated patients only. HAQ responders had lower GILZ-EC 50 values and higher GR number and $K_{D}$.

Conclusions: Baseline cellular in vitro glucocorticoid sensitivity is modestly associated with in vivo improvement in DAS and HAQ-DI score after GC bridging therapy in RA. Further studies are needed to evaluate whether in vitro GC sensitivity may support the development of tailor-made GC therapy in RA.

\section{Introduction}

Rheumatoid arthritis (RA) is a common autoimmune disorder characterized by chronic synovial inflammation, leading to joint destructions. Based on their antiinflammatory properties, glucocorticoids (GCs) have an important role in first-line treatment regimens for RA in combination with disease-modifying antirheumatic drugs (DMARDs). However, on administration of GCs, a wide spectrum of clinical responses is observed with up to $30 \%$ of patients being relatively GC resistant [1-3]. In addition, it is well known that in some patients side

\footnotetext{
*Correspondence: r.quax@erasmusmc.nl

'Department of Internal Medicine, Erasmus MC, University Medical Center,

's-Gravendijkwal 230, Rotterdam, 3015 CE, The Netherlands

Full list of author information is available at the end of the article
}

effects rapidly develop during GC therapy, whereas others tolerate GC well, independent of dose and treatment duration. This indicates that GC sensitivity is highly variable among patients.

Determinants of individual GC sensitivity include both genetic and acquired factors. Functional polymorphisms of the glucocorticoid receptor (GR) gene have been identified that modulate GC sensitivity [4]. Recently we found that these polymorphisms are also associated with RA susceptibility and disease severity [5]. Acquired, diseaserelated factors include the effects of inflammation, mediated by proinflammatory cytokines, on cellular GC sensitivity, resulting in systemic or tissue-specific GC resistance of immunocompetent cells at the site of inflammation [6].

\section{() Biomed Central}


Despite this wide variety in individual GC sensitivity, RA patients are mostly treated with standardized schedules, by using fixed GC dose and treatment duration, inevitably leading to under- or overtreatment in subsets of patients.

Considering the detrimental effects of prolonged synovial inflammation in undertreated patients and the potential severe burden of GC side effects in overtreated patients, it is obvious that a need exists for tools measuring individual GC sensitivity, allowing more tailor-made GC therapy.

GC binding capacity (that is, number and affinity of GRs) has proven its potential as a possible predictor of GC therapy outcome, as has been shown for asthma [7], systemic lupus erythematosus (SLE) [8], and leukemia [9]. In RA, both higher and lower GR expression levels have been reported [10-13]. With respect to in vivo GC therapy outcome, Huisman and co-workers [11] showed that GR levels at baseline do not correlate with clinical or radiologic outcome after 2 years of GC therapy. However, this outcome may have been influenced by concomitant use of other antirheumatic drugs.

In addition, studies in patients with inflammatory bowel disease [14], asthma [15], and RA [16] by using in vitro functional assays have shown that the degree of GC-mediated suppression of proliferation of peripheral blood mononuclear cells (PBMCs) may predict in vivo GC sensitivity. More recently, a diminished inhibitory effect of GCs on PBMC proliferation in vitro was shown in a larger cohort of GC resistant RA patients [3].

Recently, we developed in vitro bioassays to measure individual cellular GC sensitivity [17]. In these bioassays, dexamethasone-regulated expression of interleukin-2 (IL-2) and glucocorticoid-induced leucine zipper (GILZ) are measured. Transrepressive effects of GC, traditionally considered to be the predominant mechanism regulating antiinflammatory actions of GC, are represented by the IL-2 assay. The GILZ assay is an example of genes in which transcription is transactivated by GCs. Originally such genes were postulated to be responsible for the development of GC-induced side-effects $[18,19]$. By using these bioassays, a spectrum of GC sensitivity could be demonstrated in healthy individuals.

The aim of this study was to examine whether in vitro assessment of GC sensitivity of PBMCs, using both these bioassays and measurement of GC binding capacity, is associated with the in vivo response to GC treatment in patients with RA.

\section{Materials and methods}

\section{Patients}

This study was embedded in a multicenter randomized clinical trial studying persons older than 18 years presenting with recent-onset arthritis, the so-called tREACH study (treatment in the Rotterdam early arthritis cohort) [20]. The primary aim of this study is to establish the best treatment strategy for patients with early arthritis.

Patients were included if arthritis in at least one joint was observed by a rheumatologist, and complaints were present for less than 12 months. With a prediction model developed by Visser et al. [21], patients were stratified according to their risk of having persistent erosive disease after a follow-up period of 2 years (high, intermediate, and low probability). We studied 41 patients in the high-probability group. These patients were randomized to three different treatment strategies, all including GC, either oral GC (15 mg prednisone/day, two treatment arms) or intramuscular GC (single depot of methylprednisolone, $120 \mathrm{mg}$, or triamcinolone acetonide, $80 \mathrm{mg}$, one treatment arm). All tREACH patients were naïve to GCs and DMARDs (Figure 1).

After a minimum of 1 year of follow-up, the diagnosis of the patients was verified in medical documentation or, if necessary, in consultation with the treating rheumatologist.

In an independent cohort, 37 patients with established RA and active disease (FLARE study) were recruited. Active disease was defined as disease activity requiring GC therapy according to the treating rheumatologists [22]. All patients received a single intramuscular depot of GC (methylprednisolone, $120 \mathrm{mg}$, or triamcinolone acetonide, $80 \mathrm{mg}$ ). None of the FLARE patients had used GC in the last 3 months and were taking stable DMARD therapy (Figure 1). As a control group, we studied healthy laboratory employees $(n=20)$. None of the controls was using a GC.

Of the 41 high-probability patients included via the tREACH study, 38 were ultimately diagnosed as having definite RA. In this group of early RA, two patients were lost to follow-up, leaving 36 patients for complete analysis. After randomization, oral GCs were prescribed to 22 patients, and 14 patients were given a single depot of intramuscular GC. In the FLARE study, two patients were lost to follow-up for logistic reasons. In 10 patients, only one of the assays could be performed due to limited amount of PBMCs. Ultimately, 32 patients could be evaluated for binding capacity of the GC receptor, and 32 patients for the bioassay (in 27 patients, both assays were performed). Patients lost to follow-up were included in the baseline analysis (two patients in each cohort).

\section{Methods}

\section{Assessment of in vitro glucocorticoid sensitivity}

In the tREACH cohort, in vitro GC sensitivity was assessed with the GC bioassays (for logistic reasons, only enough PBMCs were available for the GC bioassays). In patients participating in the FLARE study, in vitro GC 


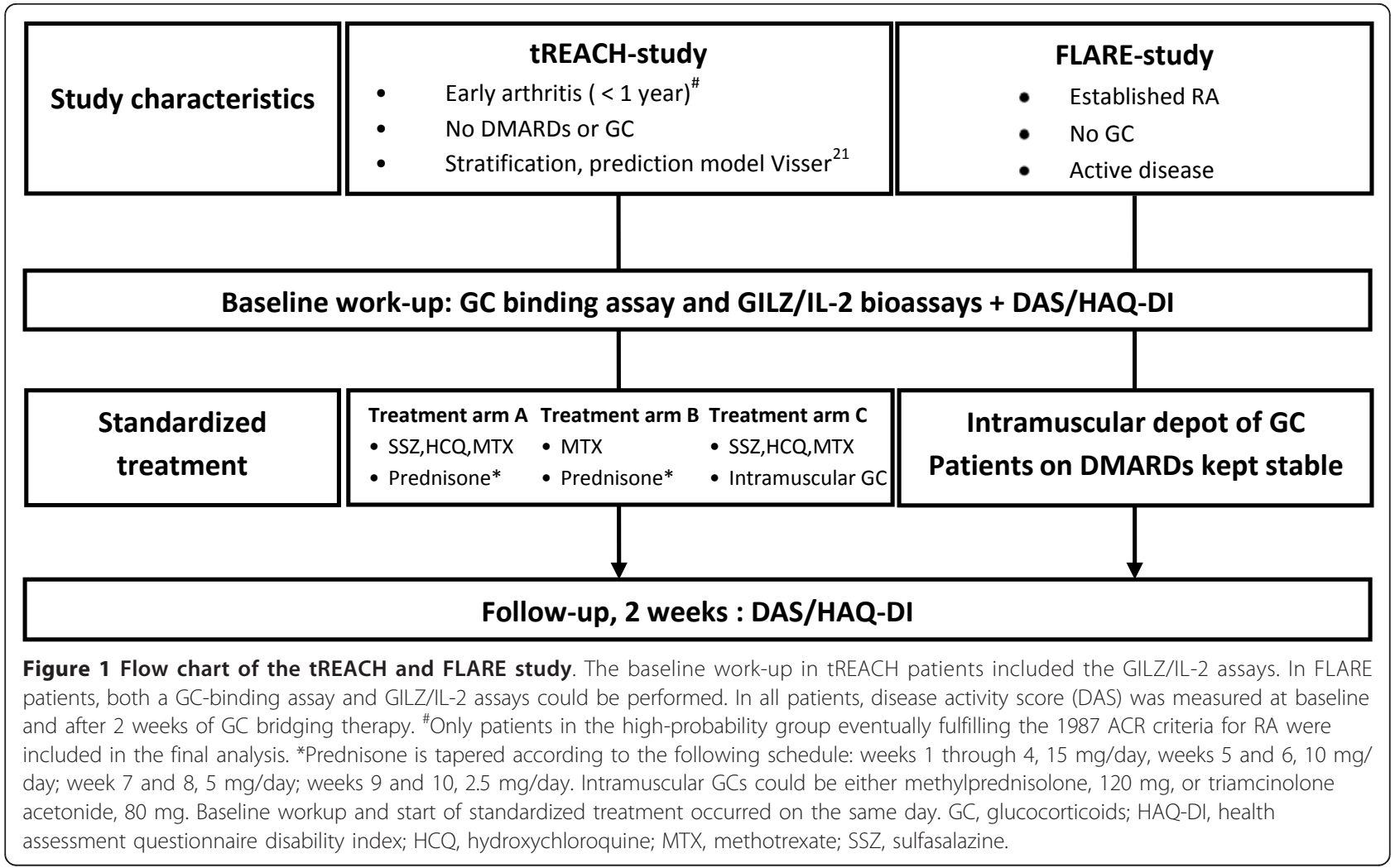

sensitivity was assessed by both the GC bioassays and GC binding capacity.

The GC bioassays were performed as described previously [17]. In short, peripheral blood was drawn in all patients before start of treatment by using Cell Preparation Tubes with Sodium Heparin (Becton Dickinson, Breda, The Netherlands), allowing isolation of PBMCs. Cells were resuspended in RPMI 1640 medium containing L-glutamine supplemented with penicillin $(100 \mathrm{U} / \mathrm{ml})$ and streptomycin $(100 \mu \mathrm{g} / \mathrm{ml})$ and $10 \%$ fetal calf serum (FCS) and precultured overnight in a 48-well plate (Costar, Amsterdam, The Netherlands, $5.0 \times 10^{5}$ cells/ well in duplicate, density of $4.0 \times 10^{6} / \mathrm{ml}$ ). A single batch of FCS was used throughout. Before use, this batch was analyzed for cortisol content, which was found to be below the detection limits.

Trypan blue staining revealed the viability of isolated cells to be greater than $95 \%$. The next day, cells were incubated with dexamethasone $0,0.33,1,3.3,10,33,100$, and $333 \mathrm{n} M$ dexamethasone and stimulated with $10 \mu \mathrm{g} / \mathrm{ml}$ phytohemagglutinin (Sigma-Aldrich, Zwijndrecht, The Netherlands). After 4 hours in the incubator, total RNA of the cells was collected (Total RNA isolation Kit, Roche, Almere, The Netherlands). Reverse transcription was performed by using $100 \mathrm{ng}$ total RNA per reaction. Quantitative real-time PCR analysis was carried out on a 7900HT Taqman machine (Applied Biosystems, Nieuwerkerk aan den IJssel, The Netherlands), according to the manufacturer's instructions. Data were analyzed by using the SDS 2.4 software (Applied Biosystems). GC-specific transactivation of the GILZ gene and transrepression of the $I L-2$ gene were measured while correcting for the housekeeping gene hypoxanthine phosphoribosyltransferase (HPRT) by using the $\triangle \triangle C T$ method; primers and probes were obtained from Biolegio, Nijmegen, The Netherlands (see Additional File 1 Table S1). Half-maximal effective concentration $\left(\mathrm{EC}_{50}\right)$ was calculated by using nonlinear regression in GraphPad Prism 5.0 and used as a read-out for in vitro $\mathrm{GC}$ sensitivity. The $\mathrm{EC}_{50}$ values of GILZ and IL-2 in PBMCs were not significantly influenced by the cellular composition (percentages lymphocytes and monocytes) of the PBMCs (data not shown).

GC binding capacity was measured by using a wholecell dexamethasone-binding assay, as described previously, with minor modifications [23]. In brief, by using PBMCs from the same isolation procedure, incubation was started in a volume of $200 \mu \mathrm{l}\left(0.5\right.$ to $2 \times 10^{6}$ cells $)$ containing $\left[{ }^{3} \mathrm{H}\right]$ dexamethasone at concentrations of 1 to $30 \mathrm{n} M$ with and without a 400-fold excess of unlabeled dexamethasone reflecting nonspecific and total binding of $\left[{ }^{3} \mathrm{H}\right]$ dexamethasone, respectively. Two tubes without labeled dexamethasone were incubated under the same conditions for determination of cell number and viability at the end of the procedure. The PBMCs were incubated 
during 1 hour at $30^{\circ} \mathrm{C}$ in a shaking water bath. The incubation was stopped by the addition of $2 \mathrm{ml}$ cold saline, followed by centrifugation and two washing steps. Finally, the PBMCs were resuspended in $250 \mu \mathrm{l}$ saline. Radioactivity in $200 \mu \mathrm{l}$ of this suspension was counted in a liquid scintillation counter. Specific binding was calculated by subtracting nonspecific binding from total binding. $\mathrm{EC}_{50}$ values, receptor number, and ligand affinity $\left(1 / K_{D}\right)$ were calculated by using the nonlinear regression method (GraphPad Prism, version 5.0; La Jolla, CA, USA).

\section{In vivo glucocorticoid sensitivity}

Trained research nurses examined patients before and after 2 weeks of standardized GC treatment. Disease Activity Score (DAS, 44 joints) was calculated according to the following formula: DAS $=0.54 \times \sqrt{ } \mathrm{RAI}+0.065 \times$ SJC44 + $0.33 \times \ln ($ ESR $)+0.007 \times$ GH $($ RAI, Ritchie Articular Index; SJC44, 44 swollen-joint count; ESR, erythrocyte sedimentation rate; $\mathrm{GH}$, general health on a 100 $\mathrm{mm}$ scale). As primary outcome, the relative decrease in DAS $\left(100 \times\left(\left(\right.\right.\right.$ DAS $\left._{\text {baseline }}-\mathrm{DAS}_{\text {after } 2 \text { weeks }}\right) /$ DAS $\left.\left._{\text {baseline }}\right)\right)$ was used as an index for in vivo GC sensitivity. By using this continuous outcome variable, a floor effect in patients with relatively low disease activity was prevented. In addition, continuous variables represent the full information, in contrast to (arbitrary) categoric data (that is, response criteria). We chose a 2-week interval for follow-up in tREACH patients to minimize the influence of the diseasemodifying effects of the other antirheumatic drugs on the DAS. A similar follow-up period was chosen in the FLARE study to make comparisons between the groups possible. During the study period, the dose of DMARD(s) already being used was not changed, and no additional anti-rheumatic therapy was started.

To explore further the effectiveness of GC therapy, the impact of GC treatment on performing activities of daily living was assessed by using the health assessment questionnaire disability index score (HAQ-DI). The HAQ-DI is a widely used and validated tool to quantify functional disability in RA [24] and comprises questions about different aspects of daily life. In particular, the minimal import difference (MID) in the HAQ-DI score is the smallest difference in HAQ-DI score that patients sense as a difference. In clinical trials, the MID in HAQ-DI improvement ranged from 0.22 to $0.24[16,17]$. As a result, patients were classified as responder (HAQ-DI $\mathrm{I}_{\text {baseline }}$ - HAQ$\mathrm{DI}_{2 \mathrm{wks}} \geq 0.25$ ) or nonresponder (HAQ-DI $\mathrm{D}_{\text {baseline }}$ $\left.\mathrm{HAQ}-\mathrm{DI}_{2 \mathrm{wks}}<0.25\right)$.

\section{Glucocorticoid-induced side effects}

We measured blood pressure and body weight before and after 3 months of GC therapy in tREACH patients. Furthermore, glycosylated hemoglobin $\left(\mathrm{HbA}_{1 \mathrm{c}}\right)$ was measured at baseline and after 3 months in tREACH patients $\left(\mathrm{HbA}_{1 \mathrm{c}}\right.$ analyzer, type Adams A1c HA-8160, Menarini Benelux).

\section{Statistical analysis}

Differences in continuous variables between the cohorts were tested by using analysis of variance (ANOVA). GILZ-EC ${ }_{50}$ values were normally distributed (Kolmogorov-Smirnoff $P>0.20$ ), whereas IL-2-EC $\mathrm{E}_{50}$ was square-root transformed, and the number of receptors and $K_{D}$ were both natural logarithm transformed to normalize the data. Bonferroni post hoc tests were used to correct for multiple testing.

Pearson or Spearman correlation coefficients were used to describe the bivariate relations between in vitro parameters of GC sensitivity and DAS at baseline and relative decrease in DAS.

ANOVA analysis was applied to test for differences in in vitro parameters of GC sensitivity between HAQ responders and nonresponders. Paired $t$ tests or Wilcoxon Signed Ranks Tests were used for analysis of alterations in DAS, HAQ-DI scores, blood pressure, body weight, and $\mathrm{HbA}_{1 \mathrm{c}}$ values.

To test for potential confounders, each of the individual in vitro parameters of GC sensitivity (that is, IL-2- and GILZ-EC ${ }_{50}, K_{D}$, and number of GRs) and selected covariates were modeled by using linear regression (relative decrease in DAS as the dependent variable). These selected covariates included gender, age, and, based on potential synergistic immunomodulating properties with GCs, use of NSAIDs, number of DMARDs, and use of anti-TNF- $\alpha$ agents.

Orally and intramuscularly treated patients were analyzed separately because of nonequivalent cumulative dosages of GC (cumulative GC dosage: oral > intramuscular). We considered differences statistically significant if $P \leq 0.05$ (two-sided).

\section{Ethical approval}

All subjects signed informed consent, and the study was approved by the medical ethics committee of the Erasmus Medical Center.

\section{Results}

Thirty-eight tREACH patients and 37 FLARE patients were prospectively studied. Patients in the FLARE study had a significantly higher disease activity at baseline, a longer duration of disease, and a higher percentage of erosions compared with tREACH patients. Further baseline characteristics are summarized in Table 1.

\section{Baseline in vitro glucocorticoid sensitivity in RA and healthy controls}

Overall, patients with early (tREACH cohort) and established RA (FLARE cohort) had higher mean $\mathrm{EC}_{50}$ values 
Table 1 Patient characteristics

\begin{tabular}{|c|c|c|c|}
\hline & Controls $(n=20)$ & TREACH $(n=38)$ & FLARE $(n=37)$ \\
\hline Female gender, $n(\%)$ & $10(50)$ & $25(65.8)$ & $25(67.6)$ \\
\hline Age in years, mean (SD) & $31.8(9.7)$ & $53.3(13.98)^{a}$ & $53.7(13.40)^{\mathrm{a}}$ \\
\hline Disease duration in months, median (range) & - & $5.4(2-12)$ & $73.0(0-414)^{b}$ \\
\hline Presence of joint erosions, $n(\%)$ & - & $10(26.3)$ & $20(54.1)^{c}$ \\
\hline Anti-CCP positive, $n(\%)$ & - & $30(78.9)$ & $24(85.7)^{d}$ \\
\hline Rheumatoid factor (IgM) positive, $n(\%)$ & - & $31(81.6)$ & $27(73.0)$ \\
\hline DAS44 at baseline, mean (SD) & - & $3.05(0.92)$ & $3.57(0.95)^{c}$ \\
\hline HAQ-DI at baseline, mean (SD) & - & - & $1.43(0.62)$ \\
\hline Use of NSAID, $n(\%)$ & - & $25(67.6)$ & $19(51.4)$ \\
\hline Use of methotrexate, $n(\%)$ & - & - & $22(59.5)$ \\
\hline Use of hydroxychloroquine, $n(\%)$ & - & - & $11(29.7)$ \\
\hline Use of sulfasalazine, $n(\%)$ & - & - & $5(13.5)$ \\
\hline Number of DMARDs, median (range) & - & - & $1(0-3)^{\mathrm{e}}$ \\
\hline Use of anti-TNF- $\alpha$ therapy, $n$ (\%) & - & - & $5(13.5)$ \\
\hline
\end{tabular}

DAS44, Disease Activity Score, 44 joints; HAQ-DI, Health Assessment Questionnaire Disability Index. ${ }^{\text {a }} P<0.001$ as compared with healthy controls; ${ }^{\text {b }} P<0.001$ as compared with tREACH patients; ${ }^{c} P<0.05$; ${ }^{d}$ anti-CCP was not routinely analyzed; percentage is based on 28 patients with known anti-CCP status; ${ }^{e}$ Seven patients were not using any DMARD at the time of assessment.

in the IL-2 assay than did healthy controls (although not statistically significant in the FLARE cohort), indicating that RA patients needed a higher dosage of dexamethasone to suppress IL-2 mRNA expression in vitro. In contrast to this, similar $\mathrm{EC}_{50}$ values were measured in the GILZ assay (Figure 2A, C). Patients participating in the FLARE study had a higher number of GRs compared with healthy controls, while having comparable affinity $\left(1 / K_{D}\right)$ of the receptor (Figure $\left.2 E, F\right)$. The percentage of monocytes was measured in subsets of FLARE patients and healthy controls and did not differ significantly (mean \pm SD, $24.6 \pm 9.2$ in FLARE patients versus $20.9 \pm 5.0$ in healthy controls). Ligand affinity of monocytes and lymphocytes did not differ significantly. The number of glucocorticoid receptors per cell was about threefold higher in monocytes as compared with lymphocytes (data not shown). The maximum induction of GILZ and repression of IL-2 tended to be lower in the established RA cohort as compared with healthy controls $(P=0.068$ and $P=0.101$, respectively) (Figure $2 \mathrm{~B}, \mathrm{D})$.

No correlations were found between the DAS and parameters of in vitro GC sensitivity. Of the variables used to calculate the DAS, a negative association was observed between the RAI and IL-2-EC 50 ( $\rho=-0.465$; $P=0.005$ ), but only in the early RA patients. No gender differences were noted at the mean level of the IL-2$\mathrm{EC}_{50}$ and GILZ-EC $\mathrm{E}_{50}$, number of GRs, or the affinity of the receptor.

HAQ-DI sum scores before start of treatment did not show any correlations with in vitro parameters of GC sensitivity. Male and female individuals did not differ significantly in HAQ-DI sum scores.

\section{Correlation between in vitro parameters of glucocorticoid} sensitivity

GILZ-EC ${ }_{50}$ and IL-2-EC $\mathrm{E}_{50}$ were positively correlated, but only in the patients with early RA $(\rho=0.383 ; P=$ 0.028). In patients with established RA, the number of GRs was inversely correlated with GILZ-EC $\mathrm{E}_{50}$ and IL-2$\mathrm{EC}_{50}(\rho=-0.401 ; P=0.042$; and $\rho=-0.462 ; P=0.020$ respectively). $K_{\mathrm{D}}$ was also inversely correlated with GILZ-EC $_{50}(\rho=-0.413 ; P=0.032)$, but not with IL-2$\mathrm{EC}_{50}$. Finally, $\mathrm{K}_{\mathrm{D}}$ and GR-number were correlated ( $\rho=$ 0.627; $P<0.001$; see Additional File 2 Figure S2).

\section{Pretreatment in vitro glucocorticoid sensitivity and disease activity in RA after 2 weeks of glucocorticoid therapy} After 2 weeks of GC treatment, a significant decrease in disease activity was measured in both orally and intramuscularly treated patients $\left(\triangle \mathrm{DAS}_{\text {oral }}=0.92 ; P<0.001\right.$; $\triangle \mathrm{DAS}_{\text {intramuscular }}=0.89 ; P<0.001$; and see Additional File 3 Table S3). The interquartile range in relative decrease in DAS was $22 \%$ and $43 \%$ in orally and intramuscularly treated patients, respectively, indicating greater variability in relative decrease in DAS in the intramuscularly treated group.

In patients treated with a single intramuscular depot of GC (all FLARE patients and a proportion of tREACH patients), a modest inverse relation was found between in vitro $\mathrm{GC}$ sensitivity as reflected by IL-2-EC $\mathrm{E}_{50}$ values and the percentage improvement in DAS after 2 weeks $(P=$ 0.029; Figure 3A). Similarly, near-significance was reached for GILZ-EC $\mathrm{E}_{50}$ values and the relative decrease in DAS, but also only in intramuscularly treated patients $(P=0.054 ;$ Figure $3 \mathrm{~B})$. In addition, the number of GRs 


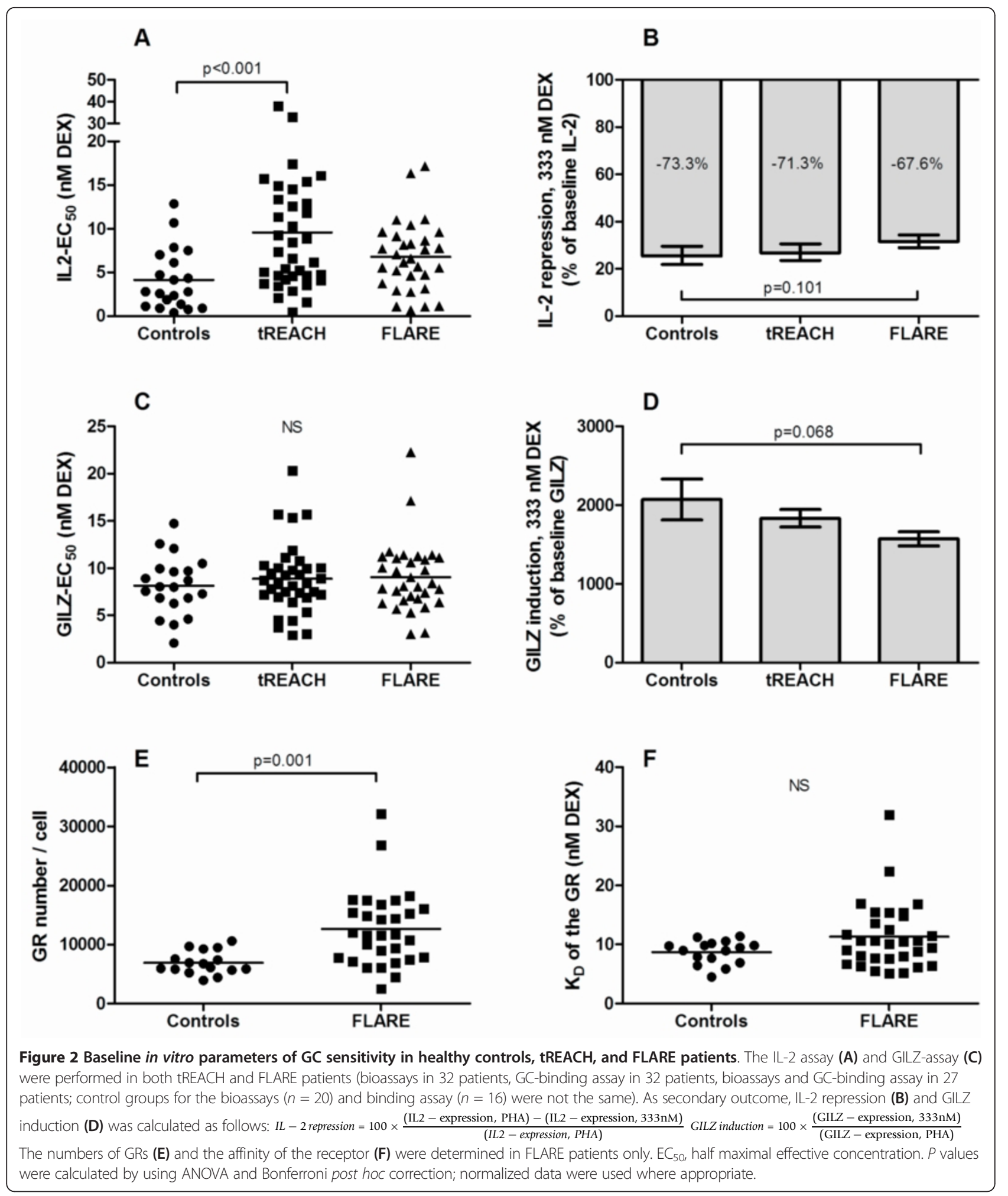

displayed a modest positive relation with the improvement in DAS in patients with intramuscular depots of $\mathrm{GC}$, and a positive trend was observed for the $\mathrm{K}_{\mathrm{D}}$ of the GRs $(P=0.008$ and $P=0.070$, respectively; Figure $3 \mathrm{C}, \mathrm{D})$.
With multiple regression, however, both the number of GRs and $K_{D}$ of the receptor were significant factors contributing to the relative decrease in DAS. The negative association between IL-2-EC $\mathrm{E}_{50}$ and GILZ-EC $\mathrm{E}_{50}$ 


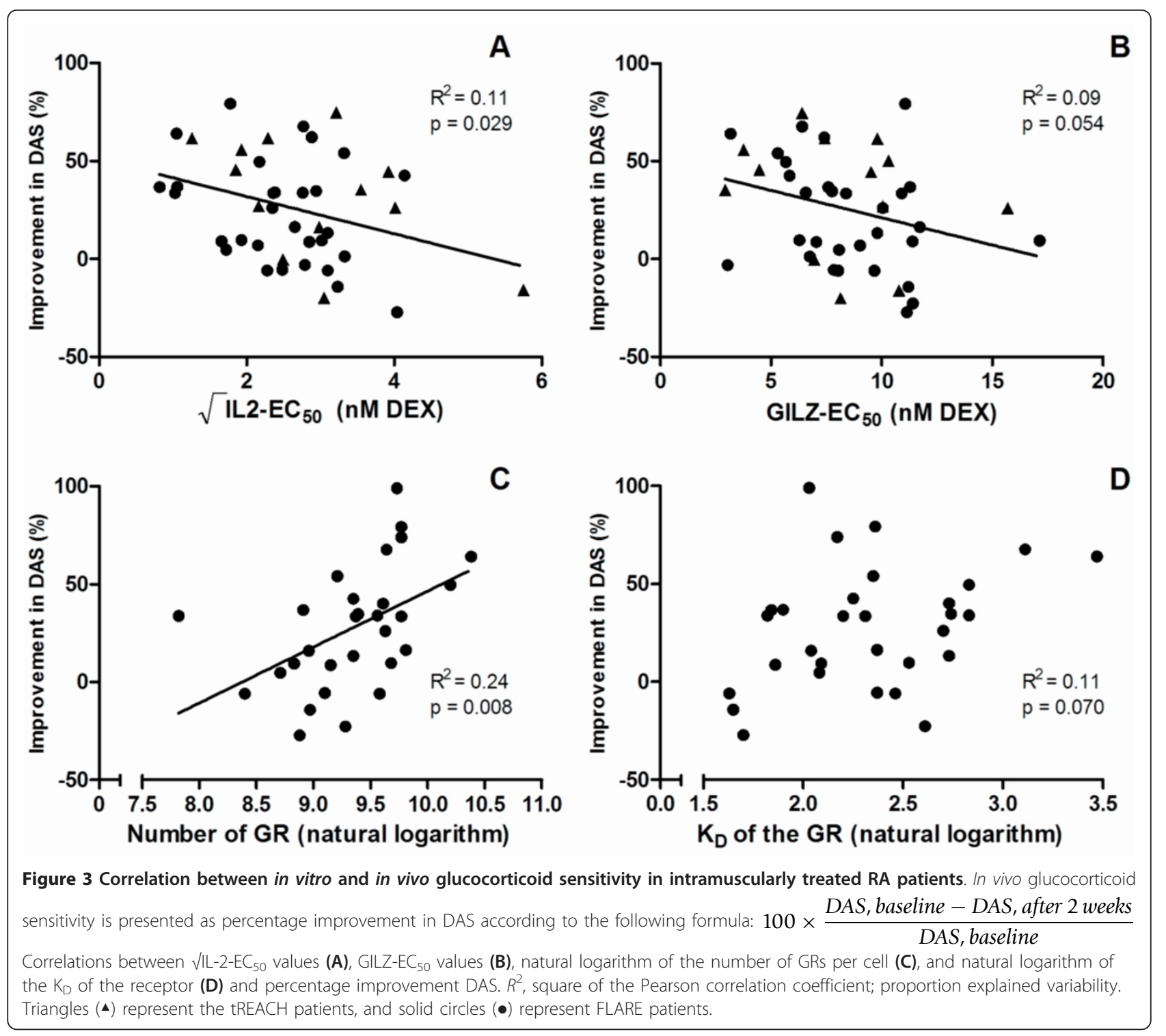

values and relative decrease in DAS persisted, although only near-significance was reached (Table 2).

Of note, in the subgroup of patients with evaluation of GC-binding capacity (FLARE study), age and use of NSAIDs were also independent predictors of improvement of disease activity after 2 weeks of GC treatment. Age and use of NSAIDs both had positive $\beta$ coefficients, indicating a better response with older age and use of NSAIDs.

Pretreatment in vitro glucocorticoid sensitivity and functional disability in RA after 2 weeks of glucocorticoid therapy

After 2 weeks of GC treatment, a significant decrease in HAQ-DI sum scores was measured $(\triangle \mathrm{HAQ}-\mathrm{DI}=-0.40$; $P<0.001)$. However, 12 of 34 patients still had to be classified as nonresponders. Responders had lower $\mathrm{EC}_{50}$ values of GILZ and higher numbers of GRs with higher $K_{D}$ (Figure 4). IL-2-EC $C_{50}$ values tended to be lower in responders.

In vitro glucocorticoid sensitivity and development of glucocorticoid-mediated metabolic side effects

The mean systolic and diastolic blood pressure of patients was reduced at their 3-month follow-up visit (systolic $\mathrm{RR}_{\text {baseline, }} 145.0 \mathrm{~mm} \mathrm{Hg}$; systolic $\mathrm{RR}_{3}$ months, 134.4 mm Hg; $P=0.005$; and diastolic $\mathrm{RR}_{\text {baseline }}$, 87.4 mm Hg; diastolic $\mathrm{RR}_{3}$ months $82.6 \mathrm{~mm} \mathrm{Hg;} P=0.003$ ). This decrease was observed in both orally and intramuscularly treated patients. Body mass index did not change significantly after 3 months $\left(\mathrm{BMI}_{\text {baseline, }}\right.$ 26.9; $\mathrm{BMI}_{3}$ months, 26.7). 
Table 2 In vitro parameters of GC sensitivity and relative decrease in DAS

\begin{tabular}{|c|c|c|c|c|c|}
\hline \multirow[t]{2}{*}{ Bioassays } & \multicolumn{5}{|c|}{ GC binding assay } \\
\hline & $\beta(95 \% \mathrm{Cl})^{a}$ & $P$ value & & $\beta(95 \% \mathrm{Cl})^{\mathrm{a}}$ & $P$ value \\
\hline IL-2-EC 50 & $-0.014(-0.028-0.001)$ & 0.058 & $K_{D}$ & $0.03(0.014-0.046)$ & 0.001 \\
\hline Age & $0.005(-0.002-0.110)$ & 0.161 & Age & $0.009(0.002-0.017)$ & 0.020 \\
\hline Gender & $0.128(-0.057-0.312)$ & 0.169 & Gender & $0.199(0.013-0.385)$ & 0.037 \\
\hline Use of NSAID & $0.087(-0.087-0.261)$ & 0.316 & Use of NSAID & $0.212(0.025-0.400)$ & 0.028 \\
\hline Number of DMARDs & $0.023(-0.079-0.125)$ & 0.647 & Number of DMARDs & $0.112(0.004-0.221)$ & 0.043 \\
\hline Use of anti-TNF- $\alpha$ & $0.008(-0.283-0.299)$ & 0.955 & Use of anti-TNF- $\alpha$ & $0.222(-0.010-0.455)$ & 0.060 \\
\hline GILZ-EC 50 & $-0.023(-0.046-0.001)$ & 0.062 & GR number/1,000 & $0.027(0.012-0.042)$ & 0.001 \\
\hline Age & $0.006(-0.001-0.014)$ & 0.079 & Age & $0.010(0.002-0.018)$ & 0.015 \\
\hline Gender & $0.116(-0.075-0.308)$ & 0.225 & Gender & $0.017(-0.188-0.223)$ & 0.862 \\
\hline Use of NSAID & $0.181(-0.004-0.366)$ & 0.055 & Use of NSAID & $0.203(0.006-0.400)$ & 0.044 \\
\hline Number of DMARDs & $0.021(-0.085-0.126)$ & 0.695 & Number of DMARDs & $0.084(-0.027-0.195)$ & 0.132 \\
\hline Use of anti-TNF- $\alpha$ & $0.023(-0.270-0.320)$ & 0.874 & Use of anti-TNF- $\alpha$ & $0.129(-0.121-0.378)$ & 0.297 \\
\hline
\end{tabular}

In all four models, relative decrease in DAS was the dependent variable. The data represent the combined bioassays from intramuscularly treated patients with early $(n=14)$ and established RA $(n=31)$. GILZ-EC 50 and IL-2-EC 50 were not associated with relative decrease in DAS in orally treated patients in recent-onset RA ( $n=22$ ). The GC-binding assay is performed only in established RA ( $n=30$, all intramuscular GC). ${ }^{2}$ Values represent adjusted $\beta$-coefficients and $95 \%$ confidence intervals.

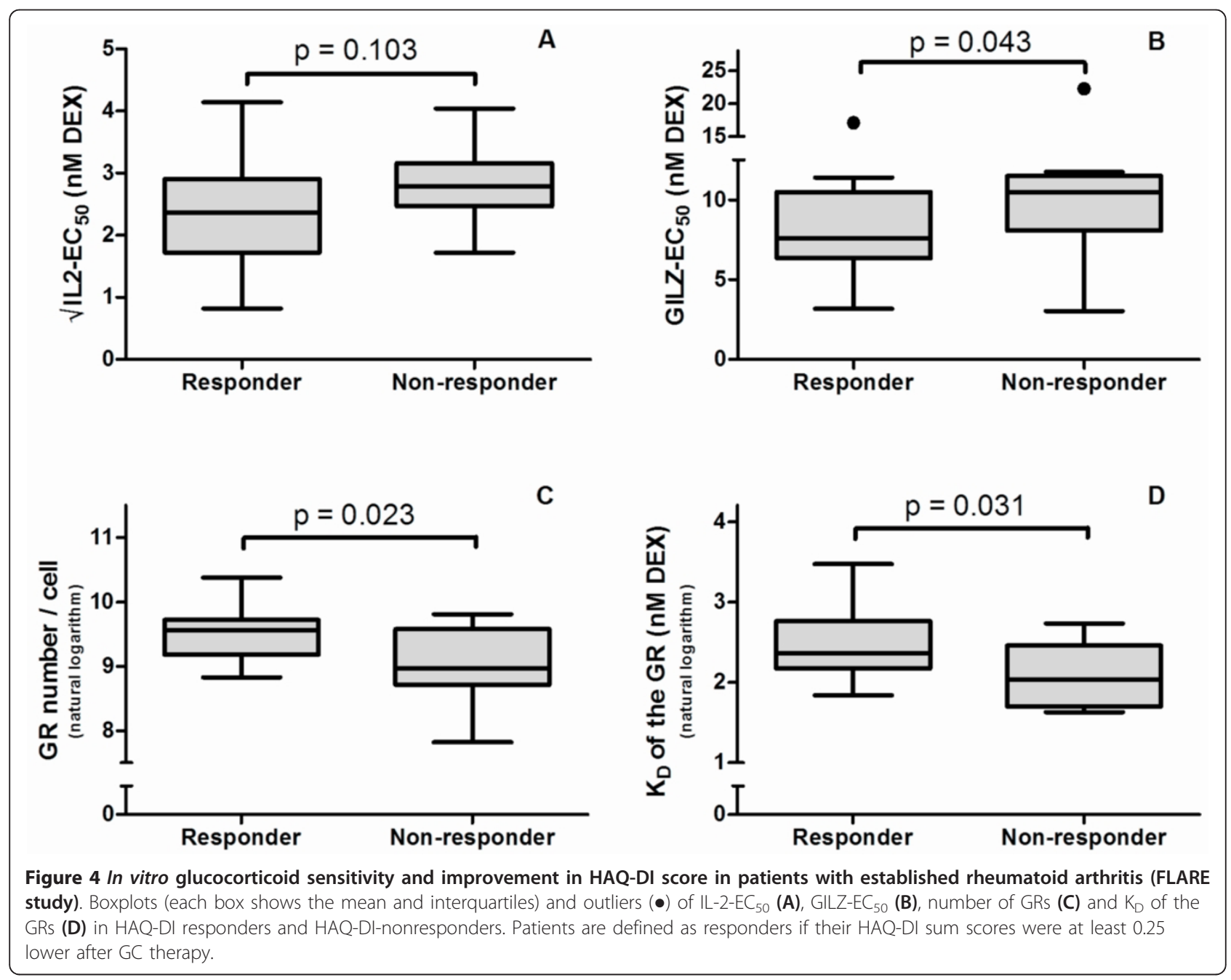


At baseline, the mean $\mathrm{HbA}_{1 \mathrm{C}}$ was $5.51 \%$ (reference range, $4.5 \%$ to $6.0 \%$ ). Three patients had $\mathrm{HbA}_{1 \mathrm{C}}$ values above the upper limit of the normal range. After 3 months, the mean $\mathrm{HbA}_{1 \mathrm{C}}$ was even somewhat lower (5.31\%; $P=0.016)$. Nine patients had a higher $\mathrm{HbA}_{1 \mathrm{C}}$, four patients had an equal percentage of $\mathrm{HbA}_{1 \mathrm{C}}$, and 13 patients had an improvement. No relation was found between alterations in $\mathrm{HbA}_{1 \mathrm{C}}$ and blood pressure and in vitro $\mathrm{GC}$ sensitivity, as measured by the bioassay.

\section{Discussion}

We examined whether in vitro GC sensitivity is associated with the clinical response to GC treatment in RA. Our results show that, in particular, the number of GRs in PBMCs and the $\mathrm{K}_{\mathrm{D}}$ of the GRs correlated with in vivo GC sensitivity, as reflected by the relative decrease in DAS. Near-significant associations were found between dexamethasone-mediated changes in IL-2- and GILZmRNA expression levels and the relative decrease in DAS. Similar patterns between clinically relevant improvement in HAQ-DI sum scores and in vitro parameters of GC sensitivity were observed.

Remarkably, PBMCs of RA patients have a decreased in vitro capacity for transrepression, which is most pronounced in the early RA cohort. This transrepression of proinflammatory cytokine production by (endogenous) GC is an important mechanism to counteract the inflammatory response [25]. Consequently, reduced transrepression might hamper the resolution of acute inflammation, governing the evolution into a chronic phase of inflammation, a central feature of many autoimmune diseases. Interestingly, polymorphisms of the GR gene associated with reduced (that is, 9 3 ) or increased (that is, Bcll and N363S) GC sensitivity are associated with increased respectively decreased susceptibility to RA [5]. Next to decreased GC sensitivity, a blunted hypothalamicpituitary-adrenal axis has been postulated to be part of the pathophysiology of RA [26].

Importantly, we did not find a relation between disease activity and in vitro GC sensitivity, suggesting that the impaired GC sensitivity is not just due to increased levels of proinflammatory cytokines. This is in accordance with the study performed by Hearing and co-workers [14], who also did not find a relation between disease activity and in vitro GC sensitivity in inflammatory bowel disease.

In contrast to this reduced GC sensitivity at the transcriptional level, we found a higher number of GRs in patients with established RA. A large study by Schlaghecke et al. [13] showed lower numbers of GR in RA. In contrast, Eggert and co-workers [10] found increased expression of GR, which dramatically decreased after long-term GC treatment. Interestingly, the only study with longitudinal data on GR expression in RA reports an increase in GR expression over time in female RA patients, suggesting a compensatory mechanism for the ongoing inflammatory state [11]. In addition to this concept, the higher numbers of GRs in our cohort might be interpreted as a counterbalancing mechanism for the reduced GC sensitivity. In line with this hypothesis, we found a correlation between higher numbers of GRs and lower $\mathrm{EC}_{50}$ values of GILZ and IL-2.

GC exert their antiinflammatory properties via the GR. On binding of GC to the GRs, the receptor-ligand complex migrates to the nucleus to interact with GC-responsive elements of target genes. During inflammation, cellular GC sensitivity can be modulated by cytokines via effects on GR number and affinity, GR translocation to the nucleus, interaction with inflammatory transcription factors (for example, NF- $\kappa$ B, AP- 1 ) and expression of the GR- $\beta$ splice variant [27]. The assessment of GC-mediated gene expression, as performed in our bioassay, may have the advantage of integrating all postreceptor downstream factors that modulate GC sensitivity. Originally, the immunosuppressive effects of GC were attributed to transrepression of immune genes. We indeed found that IL-2 $\mathrm{EC}_{50}$ values are moderately associated with the relative decrease in DAS. However, in the last decade, increasing evidence has been obtained pointing toward immunomodulating effects of GC-activated genes [28].

In this perspective, the GILZ gene studied in our bioassay is of particular interest. GILZ can directly interfere with the AP-1 complex [29] and can also inhibit NF- $\kappa$ B nuclear translocation and DNA binding in vitro [30]. Recently, GILZ has been demonstrated to function as an endogenous inhibitor of chronic inflammation in a murine model of RA [31]. In addition, GILZ transgenic mice are less prone to develop T-helper 1-mediated colitis [32]. We extend these observations by demonstrating that GILZ regulation by dexamethasone in vitro might be a potential marker for in vivo effects of GC therapy in humans.

Remarkably, the predictive value of the GILZ and IL-2 assays is found only in the intramuscularly treated patients and not in the orally treated patients. A possible explanation is that the higher dosage of GCs used in the orally treated patients masks subtle differences in GC sensitivity. This is supported by the fact that the interquartile range in relative decrease in DAS was higher in the intramuscularly treated patients. Furthermore, a lack of compliance in orally treated patients could play a role, whereas this problem is obviously not present in intramuscularly treated patients. Finally, differences in pharmacokinetics and duration of disease could also be causes adding to observed differences between orally and intramuscularly treated patients.

In our group of patients with established RA, both the number of GRs and the $K_{D}$ were positively correlated with improvement in disease activity. From a biologic point of view, higher numbers of receptors correlating 
to better response seems plausible. Indeed, GR levels have been shown to serve as possible markers of GCtherapy outcome in SLE and leukemia [8,9]. Conversely, our observations concerning the $\mathrm{K}_{\mathrm{D}}$ of the GRs are in contrast to other reports [7,33]. In this perspective, it is important to note that higher numbers of GRs were accompanied by lower affinity of the receptor (that is, a higher $\mathrm{K}_{\mathrm{D}}$ ) in several other conditions [7,33-37].

Whether this phenomenon truly occurs in vivo or represents an artificial correlation (because $K_{D}$ and GR number are calculated from the same data) is yet unclear. Analysis of GR number and $K_{D}$ separately by using different techniques could possibly give more insight into this intriguing observation. Clearly, the interpretation of binding assays should be done with caution.

Although we did not measure serum levels of the exogenously administered GCs in our patients, the (average) serum concentrations of these GCs, in the doses administrated, are reported to be in the same (equipotent) range as the GILZ and IL-2 $\mathrm{EC}_{50}$ values and the $\mathrm{K}_{\mathrm{D}}$ of the GRs, suggesting that in vitro parameters of GC sensitivity may reflect in vivo GC sensitivity reasonably well $[38,39]$.

Unexpectedly, the IL-2/GILZ assay, integrating all determinants of GC sensitivity up to the transcriptional level, showed a weaker correlation with the in vivo response than the more-upstream GR. However, GCs also have effects that do not require gene transcription, also referred to as nongenomic effects of GCs [40]. Also in RA, nongenomic actions are important, as illustrated by rapid inhibition of leukocyte recruitment in inflamed joints after GC administration [41]. GR levels may therefore be a better predictor of in vivo GC effects, because both genomic and nongenomic actions of GCs are taken into account.

Our study clearly highlights the potential of in vitro (bio) assays as possible clinical markers for GC treatment of RA patients. Recently it was shown that assessment of early arthritis patients by a rheumatologist within 12 weeks was associated with less joint destruction and a higher chance of DMARD-free remission, as compared with patients assessed after this so-called window of opportunity [42]. This favorable outcome of early treatment could be further substantiated by effective (tailor-made) GC treatment in the window of opportunity and emphasizes the need for biomarkers of GC sensitivity before the start of GC treatment.

However, several limitations in our study must be addressed. A relatively weak correlation was found between the GILZ and IL-2 assays and in vivo glucocorticoid sensitivity, restricting the usefulness of these assays in the clinical context at this moment. Further, presumably because of the restricted period of GC treatment, we could not evaluate the potency of our bioassay and binding assay to predict susceptibility for GC-mediated side effects. Also, because GC sensitivity is highly tissue specific, extrapolation of our findings to other inflammatory disorders should be done with caution. As prednisone is a pro-drug requiring reduction by $11 \beta$-HSD type 1 , and methylprednisolone and triamcinolone acetonide are active 11-hydroxysteroids, it is possible that differences in the cortisol-cortisone shuttle, mediated by the proinflammatory state, might also have influenced in vivo GC sensitivity [43]. Furthermore local steroid metabolism in the synovial cells may play a role in increasing local cortisol and prednisolone concentration, as shown by Hardy and co-workers [44]. Considering this tissue specificity and the sample size of our RA cohort, validation of these in vitro assays should be done in cohorts with both RA and other autoimmune disorders.

\section{Conclusions}

We show that after 2 weeks of GC treatment of patients with RA, the relative decrease in DAS in vivo is modestly associated with the number and affinity of GRs. Near-significant associations were found with $\mathrm{EC}_{50}$ values of IL-2 and GILZ. In vitro identification of hypoor hypersensitive subgroups of RA patients may facilitate a more (alternatively: may facilitate individual GC therapy) individual GC therapy for these particular patients to maximize therapeutic efficacy and minimize timeand dose-dependent side effects. Further studies evaluating the number and affinity of GRs in PBMCs at baseline in relation to improvement in DAS are needed to establish whether assessment of in vitro GC sensitivity can support individualized therapeutic management of RA patients treated with GCs.

\section{Additional material}

\begin{abstract}
Additional file 1: Table S1. Primer and probe sequences for GILZ, IL-2, and HPRT. This table gives the sequences of the primers and probes used in the bioassay to measure messenger RNA levels of GILZ, IL-2, and HPRT.

Additional file 2: Figure S2. Bivariate correlations between in vitro parameters of glucocorticoid sensitivity. This figure displays how different in vitro parameters of GC sensitivity, as measured in the bioassay and GC-binding assay, correlate to each other.

Additional file 3: Table S3. DAS and individual measures of the DAS in tREACH and FLARE patients. This table provides detailed information on DAS and individual measures of the DAS in the different subsets of studied patients, both at baseline and after 2 weeks of GC treatment.
\end{abstract}

\footnotetext{
Abbreviations

ANOVA: analysis of variance; DAS: disease activity score; DMARDs: diseasemodifying antirheumatic drugs; $\mathrm{EC}_{50}$ : half-maximal effective concentration; ESR: erythrocyte sedimentation rate; GC: glucocorticoid; GH: general health at a 100-mm scale; GILZ: glucocorticoid-induced leucine zipper; GR: glucocorticoid receptor; HAQ-DI: health assessment questionnaire disability index; $\mathrm{HbA}_{1}$ : glycosylated hemoglobin; IL-2: interleukin-2; PBMC: peripheral blood mononuclear cell; RA: rheumatoid arthritis; RAl: Ritchie Articular Index; SJC44: 44 swollen-joint count; tREACH: treatment in the Rotterdam early arthritis cohort.
} 


\section{Acknowledgements}

The authors thank all patients and rheumatologists for their contribution to the tREACH study and the FLARE study. We are thankful to all research assistants for their help in data collection and to Karolina Sikorska for her excellent assistance in the statistical analysis of data. This study was supported by the Dutch Arthritis Association.

\section{Author details}

'Department of Internal Medicine, Erasmus MC, University Medical Center, 's-Gravendijkwal 230, Rotterdam, 3015 CE, The Netherlands. 'Department of Rheumatology, Erasmus MC, University Medical Center, 's-Gravendijkwal 230, Rotterdam, 3015 CE, The Netherlands. 'Department of Rheumatology, Maasstad Hospital, Maasstadweg 21, Rotterdam, 3079DZ, The Netherlands. ${ }^{4}$ Department of Rheumatology, Sint Franciscus Gasthuis, Kleiweg 500, Rotterdam, 3045PM, The Netherlands.

\section{Authors' contributions}

RAMQ participated in the study design and carried out the laboratory work, the statistical analysis, and wrote the paper. JWK participated in the study design, laboratory work, co-writing the paper, and research supervision. PHPdeJ, AEW, AMH, and DVZ participated in the study design and collection of patient data. RvH participated in the laboratory work. FHdeJ, SWJL, and JMWH participated in co-writing the paper and research supervision. RAF participated in the study design, co-writing the paper, and research supervision. All authors read and approved the final manuscript.

\section{Competing interests}

The authors declare that they have no competing interests.

Received: 15 March 2012 Revised: 10 July 2012

Accepted: 17 August 2012 Published: 24 August 2012

\section{References}

1. Chikanza LC, Panayi GS: The effects of hydrocortisone on in vitro lymphocyte proliferation and interleukin- 2 and -4 production in corticosteroid sensitive and resistant subjects. Eur J Clin Invest 1993, 23:845-850.

2. van Schaardenburg D, Valkema R, Dijkmans BA, Papapoulos S, Zwinderman AH, Han KH, Pauwels EK, Breedveld FC: Prednisone treatment of elderly-onset rheumatoid arthritis: disease activity and bone mass in comparison with chloroquine treatment. Arthritis Rheum 1995, 38:334-342.

3. Sliwinska-Stanczyk P, Pazdur J, Ziolkowska M, Jaworski J, KaminskaTchorzewska E, Lacki JK: The effect of methylprednisolone on proliferation of PBMCs obtained from steroid-sensitive and steroidresistant rheumatoid arthritis patients. Scand J Rheumatol 2007, 36:167-171.

4. Manenschijn L, van den Akker EL, Lamberts SW, van Rossum EF: Clinical features associated with glucocorticoid receptor polymorphisms: an overview. Ann N Y Acad Sci 2009, 1179:179-198.

5. van Oosten MJ, Dolhain RJ, Koper JW, van Rossum EF, Emonts M, Han KH, Wouters JM, Hazes JM, Lamberts SW, Feelders RA: Polymorphisms in the glucocorticoid receptor gene that modulate glucocorticoid sensitivity are associated with rheumatoid arthritis. Arthritis Res Ther 2010, 12:R159.

6. Barnes PJ, Adcock IM: Glucocorticoid resistance in inflammatory diseases. Lancet 2009, 373:1905-1917.

7. Sher ER, Leung DY, Surs W, Kam JC, Zieg G, Kamada AK, Szefler SJ: Steroidresistant asthma: cellular mechanisms contributing to inadequate response to glucocorticoid therapy. J Clin Invest 1994, 93:33-39.

8. Du J, Li M, Zhang D, Zhu X, Zhang W, Gu W, Feng Y, Zhai X, Ling C: Flow cytometry analysis of glucocorticoid receptor expression and binding in steroid-sensitive and steroid-resistant patients with systemic lupus erythematosus. Arthritis Res Ther 2009, 11:R108.

9. Gruber G, Carlet M, Turtscher E, Meister B, Irving JA, Ploner C, Kofler R: Levels of glucocorticoid receptor and its ligand determine sensitivity and kinetics of glucocorticoid-induced leukemia apoptosis. Leukemia 2009, 23:820-823.

10. Eggert M, Kluter A, Rusch D, Schmidt KL, Dotzlaw H, Schulz M, Pabst W, Boke J, Renkawitz R, Neeck G: Expression analysis of the glucocorticoid receptor and the nuclear factor-kB subunit p50 in lymphocytes from patients with rheumatoid arthritis. J Rheumatol 2002, 29:2500-2506.
11. Huisman AM, Siewertsz van Everdingen AA, Wenting MJ, Lafeber F, van Reesema DR, Jacobs JW, Bijlsma JW: Glucocorticoid receptor up-regulation in early rheumatoid arthritis treated with low dose prednisone or placebo. Clin Exp Rheumatol 2003, 21:217-220.

12. Huisman AM, Van Everdingen AA, Wenting MJ, Siewertsz Van Reesema DR, Lafeber FP, Jacobs JW, Bijlsma JW: Glucocorticoid receptor downregulation in early diagnosed rheumatoid arthritis. Ann N Y Acad Sci 2002, 966:64-67.

13. Schlaghecke R, Kornely E, Wollenhaupt J, Specker C: Glucocorticoid receptors in rheumatoid arthritis. Arthritis Rheum 1992, 35:740-744.

14. Hearing SD, Norman M, Probert CS, Haslam N, Dayan CM: Predicting therapeutic outcome in severe ulcerative colitis by measuring in vitro steroid sensitivity of proliferating peripheral blood lymphocytes. Gut 1999, 45:382-388.

15. Corrigan CJ, Brown PH, Barnes NC, Szefler SJ, Tsai JJ, Frew AJ, Kay AB: Glucocorticoid resistance in chronic asthma: glucocorticoid pharmacokinetics, glucocorticoid receptor characteristics, and inhibition of peripheral blood T cell proliferation by glucocorticoids in vitro. Am Rev Respir Dis 1991, 144:1016-1025.

16. Kirkham BW, Corkill MM, Davison SC, Panayi GS: Response to glucocorticoid treatment in rheumatoid arthritis: in vitro cell mediated immune assay predicts in vivo responses. J Rheumatol 1991, 18:821-825.

17. Smit $\mathrm{P}$, Russcher $\mathrm{H}$, de Jong FH, Brinkmann AO, Lamberts SW, Koper JW: Differential regulation of synthetic glucocorticoids on gene expression levels of glucocorticoid-induced leucine zipper and interleukin-2. J Clin Endocrinol Metab 2005, 90:2994-3000.

18. Cannarile L, Zollo O, D'Adamio F, Ayroldi E, Marchetti C, Tabilio A Bruscoli S, Riccardi C: Cloning, chromosomal assignment and tissue distribution of human GILZ, a glucocorticoid hormone-induced gene. Cell Death Differ 2001, 8:201-203.

19. Vacca A, Martinotti S, Screpanti I, Maroder M, Felli MP, Farina AR, Gismondi A, Santoni A, Frati L, Gulino A: Transcriptional regulation of the interleukin 2 gene by glucocorticoid hormones: role of steroid receptor and antigen-responsive 5'-flanking sequences. J Biol Chem 1990, 265:8075-8080

20. Claessen SJ, Hazes JM, Huisman MA, van Zeben D, Luime JJ, Weel AE: Use of risk stratification to target therapies in patients with recent onset arthritis; design of a prospective randomized multicenter controlled trial. BMC Musculoskel Disord 2009, 10:71.

21. Visser H, le Cessie S, Vos K, Breedveld FC, Hazes JM: How to diagnose rheumatoid arthritis early: a prediction model for persistent (erosive) arthritis. Arthritis Rheum 2002, 46:357-365.

22. Bingham CO, Pohl C, Woodworth TG, Hewlett SE, May JE, Rahman MU, Witter JP, Furst DE, Strand CV, Boers M, Alten RE: Developing a standardized definition for disease "flare" in rheumatoid arthritis (OMERACT 9 Special Interest Group). J Rheumatol 2009, 36:2335-2341.

23. Molijn GJ, Koper JW, van Uffelen CJ, de Jong FH, Brinkmann AO, Bruining HA, Lamberts SW: Temperature-induced down-regulation of the glucocorticoid receptor in peripheral blood mononuclear leucocyte in patients with sepsis or septic shock. Clin Endocrinol (Oxf) 1995, 43:197-203.

24. Bruce B, Fries JF: The Stanford Health Assessment Questionnaire: a review of its history, issues, progress, and documentation. J Rheumatol 2003, 30:167-178.

25. Coutinho $A E$, Chapman KE: The anti-inflammatory and immunosuppressive effects of glucocorticoids, recent developments and mechanistic insights. Mol Cell Endocrinol 2011, 335:2-13.

26. Chikanza IC, Petrou P, Kingsley G, Chrousos G, Panayi GS: Defective hypothalamic response to immune and inflammatory stimuli in patients with rheumatoid arthritis. Arthritis Rheum 1992, 35:1281-1288.

27. Silverman MN, Sternberg EM: Neuroendocrine-immune interactions in rheumatoid arthritis: mechanisms of glucocorticoid resistance. Neuroimmunomodulation 2008, 15:19-28

28. Clark AR: Anti-inflammatory functions of glucocorticoid-induced genes. Mol Cell Endocrinol 2007, 275:79-97.

29. Mittelstadt PR, Ashwell JD: Inhibition of AP-1 by the glucocorticoidinducible protein GILZ. J Biol Chem 2001, 276:29603-29610.

30. Ayroldi E, Migliorati G, Bruscoli S, Marchetti C, Zollo O, Cannarile L, D'Adamio F, Riccardi C: Modulation of T-cell activation by the glucocorticoid-induced leucine zipper factor via inhibition of nuclear factor kappaB. Blood 2001, 98:743-753. 
31. Beaulieu E, Ngo D, Santos L, Yang YH, Smith M, Jorgensen C, Escriou V, Scherman D, Courties G, Apparailly F, Morand EF: Glucocorticoid-induced leucine zipper is an endogenous antiinflammatory mediator in arthritis. Arthritis Rheum 2010, 62:2651-2661.

32. Cannarile L, Cuzzocrea S, Santucci L, Agostini M, Mazzon E, Esposito E, Muia C, Coppo M, Di Paola R, Riccardi C: Glucocorticoid-induced leucine zipper is protective in Th1-mediated models of colitis. Gastroenterology 2009, 136:530-541.

33. De Antonio SR, Saber LT, Chriguer RS, de Castro M: Glucocorticoid resistance in dialysis patients may impair the kidney allograft outcome. Nephrol Dial Transplant 2008, 23:1422-1428.

34. Schlechte JA, Ginsberg BH, Sherman BM: Regulation of the glucocorticoid receptor in human lymphocytes. J Steroid Biochem 1982, 16:69-74.

35. Perisic T, Sreckovic M, Matic G: Modulation of glucocorticoid receptor function and expression in adolescent moderate asthma. Respiration 2009, 77:70-75.

36. Elakovic I, Perisic T, Cankovic-Kadijevic M, Matic G: Correlation between glucocorticoid receptor binding parameters, blood pressure, and body mass index in a healthy human population. Cell Biochem Funct 2007, 25:427-431.

37. Schlechte JA, Sherman BM: Decreased glucocorticoid receptor binding in adrenal insufficiency. J Clin Endocrinol Metab 1982, 54:145-149.

38. Magee MH, Blum RA, Lates CD, Jusko WJ: Pharmacokinetic/ pharmacodynamic model for prednisolone inhibition of whole blood lymphocyte proliferation. Br J Clin Pharmacol 2002, 53:474-484.

39. Dasgupta B, Gray J, Fernandes L, Olliff C: Treatment of polymyalgia rheumatica with intramuscular injections of depot methylprednisolone. Ann Rheum Dis 1991, 50:942-945.

40. Limbourg FP, Liao JK: Nontranscriptional actions of the glucocorticoid receptor. J Mol Med 2003, 81:168-174.

41. Smith MD, Ahern MJ, Brooks PM, Roberts-Thomson PJ: The clinical and immunological effects of pulse methylprednisolone therapy in rheumatoid arthritis. Il. Effects on immune and inflammatory indices in peripheral blood. J Rheumatol 1988, 15:233-237.

42. van der Linden MP, le Cessie S, Raza K, van der Woude D, Knevel R, Huizinga TW, van der Helm-van Mil AH: Long-term impact of delay in assessment of patients with early arthritis. Arthritis Rheum 2010, 62:3537-3546.

43. Edwards C: Sixty years after hench: corticosteroids and chronic inflammatory disease. J Clin Endocrinol Metab 2012, 97:1443-1451.

44. Hardy R, Rabbitt EH, Filer A, Emery P, Hewison M, Stewart PM, Gittoes NJ, Buckley CD, Raza K, Cooper MS: Local and systemic glucocorticoid metabolism in inflammatory arthritis. Ann Rheum Dis 2008, 67:1204-1210.

\section{doi:10.1186/ar4029}

Cite this article as: Quax et al:: In vitro glucocorticoid sensitivity is associated with clinical glucocorticoid therapy outcome in rheumatoid arthritis. Arthritis Research \& Therapy 2012 14:R195.

\section{Submit your next manuscript to BioMed Central and take full advantage of:}

- Convenient online submission

- Thorough peer review

- No space constraints or color figure charges

- Immediate publication on acceptance

- Inclusion in PubMed, CAS, Scopus and Google Scholar

- Research which is freely available for redistribution 